\title{
Radial Neuropathy Following Surgical Procedures Conducted Under General Anesthesia -A Single-center Cross-sectional Study
}

\author{
Nasser Malekpour Alamdari, ${ }^{1,2}$ Sara Besharat, ${ }^{2}$ Maryam Abbasi,, ${ }^{2}$ and Parima Safe ${ }^{2}$ \\ 1. Critical Care Quality Improvement Research Center at Shahid Modarres Hospital, Shahid Beheshti University of Medical Sciences, Tehran, Iran; \\ 2. Clinical Research and Development Center at Shahid Modarres Hospital, Shahid Beheshti University of Medical Sciences, Tehran, Iran.
}

Itroduction: Perioperative neuropathy is a rare complication with broad scope, which can have a large negative impact on the patient's quality of life. In this paper, we aim to evaluate the incidence of perioperative radial neuropathy and potential contributors of this complication. Methods: This was a retrospective database review of surgical procedures conducted under general anesthesia between February and July 2018. Procedures were assessed for evidence of radial neuropathy. Results: A total of 2,400 cases were reviewed. Incidence of perioperative radial neuropathy was found to be $0.2 \%(n=5)$, and all the cases manifested as wrist drop. In the case (patients with perioperative radial nerve injury) and control (patients without perioperative radial nerve injury) groups, the average age of patients, mean body mass index, and mean duration of surgery were: $58.2 \pm 9.8$ and $48 \pm 0.5$ years, $24.1 \pm 4.2$ and $23.1 \pm 3.2 \mathrm{~kg} / \mathrm{m}^{2}, 5.4 \pm 1.2$ hours and $0.5 \pm 0.0$ hours, respectively. Compression of the radial nerve caused by an improper height of the arm board was found to be the most likely mechanism of nerve injury in our patients. Conclusion: Proper intraoperative positioning of the patient and paying special attention to details are among simple preventive measures that can be of great importance in enjoying an uneventful postoperative course.

\section{Keywords}

Perioperative radial neuropathy, wrist drop, surgical procedure, general anesthesia, intraoperative position

Disclosures: Nasser Malekpour Alamdari, Sara Besharat, Maryam Abbasi, and Parima Safe have no financial or non-financial relationships or activities to declare in relation to this article.

Review Process: Double-blind peer review.

Compliance with Ethics: This was a retrospective database review and did not involve any studies with human or animal subjects performed by any of the authors. Informed consent was received from all patients involved in this database review.

Authorship: The named authors meet the International Committee of Medical Journal Editors (ICMJE) criteria for authorship of this manuscript, take responsibility for the integrity of the work as a whole, and have given final approval for the version to be published.

Access: This article is freely accessible at touchNEUROLOGY.com (c) Touch Medical Media 2020.

Received: September 13, 2019

Accepted: May 1, 2020

Published Online: July 10, 2020

Citation: US Neurology. 2020;16(1):61-5

Corresponding Author: Parima Safe,

Clinical Research and Development Center,

Shahid Modarres Hospital, Yadegar-e-Emam Highway,

Tehran 1998734383, Iran. E: parimasafe@gmail.com

Support: No funding was received in

the publication of this article.
Proper intraoperative positioning is a simple, yet crucial, component of a successful operation. During each surgical procedure, a position should be employed, which not only meets the surgeon's requirements, but also has the fewest disadvantages for the patient. Peripheral neuropathies, such as those affecting the ulnar nerve, brachial plexus, lumbosacral roots, and radial nerve are among these disadvantages that fortunately occur only rarely, but can pose additional postoperative disability and financial costs to the patient. Despite intensive postoperative investigations, the precise etiology of perioperative neuropathies usually remains unclear, as a wide range of factors will contribute to this disorder: induction of anesthesia and its route, anesthetic agent and its dosage, as well as external mechanical insults during the surgery, to name a few. The true incidence of peripheral nerve injury is not known to date, and is believed to be higher than currently reported. ${ }^{1}$ Hence, studies investigating the incidence and risk factors of perioperative radial nerve injury provide clinicians with a better understanding of the problem, which can lead to a more satisfactory surgery, both for the surgeon and for the patient. This study was conducted to retrospectively appraise the incidence and possible contributors of radial neuropathy following surgical procedures carried out under general anesthesia.

\section{Materials and methods}

A retrospective review of a prospectively-maintained, single-institution database of consecutive patients undergoing a surgical procedure between February and July 2018 was performed. Informed written consent was obtained from all patients to publish this study.

All surgeries were performed by one of four board-certified surgeons in a university teaching hospital. Patients who received local or lumbar epidural anesthesia were excluded from the study. There were no limitations on the age of patients, indication of operation, type of surgical procedure performed or the intraoperative position employed. Cases of radial neuropathy following surgical procedures were evaluated by one of our surgeons and reviewed individually to ascertain that it was a complication of the surgery and not due to other contributors such as tumors, trauma, or intramuscular injections. Nerve injuries found to be due to factors other than the procedure were excluded from the study.

Demographic characteristics, comorbidities including hypertension, diabetes mellitus, arthritis, as well as surgical procedure, duration of the operation, intraoperative position, and follow-up data were 
Table 1: Variables considered in this study

\begin{tabular}{|l|l|}
\hline Variable & Type of variable \\
\hline Age & Continuous \\
\hline Gender & Nominal \\
\hline BMl & Continuous \\
\hline Duration of surgery & Continuous \\
\hline Type of surgery & Nominal \\
\hline Intraoperative position & Nominal \\
\hline
\end{tabular}

$B M I=$ body mass index .

extracted from hospital medical records. All surgeons and anesthesiologists were asked to inform the investigators about any relevant perioperative events such as hypotension, hypothermia, prolonged inflation of blood pressure cuff, changing the adjustments of operating table and arm boards (such as height and abduction degree of arm boards) within the last 6 months. In addition, operation reports were carefully investigated and perioperative blood pressure and body temperature status, as well as any report regarding changing operating table or arm board adjustments, were reviewed.

Patients were divided into two groups: the case group consisting of patients with perioperative radial neuropathy, and the control group consisting of patients with no evidence of radial nerve injury following surgical procedures. Age, gender, body mass index (BMI), type of surgery, duration of surgery, and perioperative position of all the patients, as well as comorbidities, nutrition status, intraoperative blood pressure and body temperature of patients in the case group were recorded.

Incidence of perioperative radial neuropathy was the outcome of interest in this study. The secondary outcome was to investigate possible factors for perioperative radial nerve injury based on the observational study design. Statistical analysis was done using SPSS software version 25.0 (IBM SPSS Statistics, Chicago, IL, USA). Table 1 depicts variables considered in our study. Continuous variables were expressed as the mean \pm standard deviation (SD), and qualitative data were described as absolute frequencies and proportions.

\section{Results}

By applying the aforementioned inclusion and exclusion criteria, a total of 2,400 patients who underwent a surgical procedure under general anesthesia were included in the study. Among these, five surgeries (0.2\%) were complicated by radial nerve palsy, manifesting as wrist drop (case group). Patients without perioperative radial neuropathy $(n=2,395)$, were considered as the control group. Table 2 summarizes the demographic characteristics of the two study groups, including gender distribution, mean age, BMI, and duration of surgery, as well as type of surgeries, and perioperative positioning.

The mean age of patients in the control group was $48.0 \pm 0.5$ years (range 2-92 years). The mean age of patients in the case group was $58.2 \pm 9.8$ years (range $45-72$ years), and BMl was $19.2-29.6 \mathrm{~kg} / \mathrm{m}^{2}$; two (40\%) of the patients were overweight (BMl $>25 \mathrm{~kg} / \mathrm{m}^{2}$ ), and the operations had lasted 3.5-7.0 hours. Patients in the case group were in optimal nutrition condition. No perioperative hypotension (mean arterial pressure $<65 \mathrm{mmHg}$ ) or hypothermia (core temperature $<36^{\circ} \mathrm{C}$ ) had occurred in the
Table 2: Demographic characteristics of study participants

\begin{tabular}{|l|l|l|}
\hline & $\begin{array}{l}\text { Control group } \\
(\mathrm{n}=2,395)\end{array}$ & $\begin{array}{l}\text { Case group } \\
(\mathrm{n}=5)\end{array}$ \\
\hline Age (years) & $48.0 \pm 0.5$ & $58.2 \pm 9.8$ \\
\hline Gender (female/male) & $41 \% / 59 \%$ & $20 \% / 80 \%$ \\
\hline BMI (kg/m $)$ & $23.1 \pm 3.2$ & $24.1 \pm 4.2$ \\
\hline Duration of surgery (decimal hours) & $0.5 \pm 0.0$ & $5.4 \pm 1.2$ \\
\hline Type of surgery (laparoscopy/laparotomy) & $30 \% / 70 \%$ & $40 \% / 60 \%$ \\
\hline Intraoperative position & $100 \%$ supine & $100 \%$ supine \\
\hline
\end{tabular}

Unless stated otherwise, values presented are means $\pm S D$. BMI = body mass index; $S D=$ standard deviation

five patients in the case group. More details of the case group and surgical procedures complicated by radial neuropathy can be found in Tables 3 and 4 , respectively.

In all 2,400 patients, induction and maintenance of general anesthesia was achieved using routine anesthetic agents and routine dosages (fentanyl 2-20 $\mu \mathrm{g} / \mathrm{kg}$ intravenous [IV] dose, followed by $1-2 \mu \mathrm{g} / \mathrm{kg} / \mathrm{hour}$ IV for maintenance; midazolam $0.02-0.10 \mathrm{mg} / \mathrm{kg} \mathrm{IV} ; 2 \%$ lidocaine $1.0 \mathrm{mg} / \mathrm{kg}$ IV; propofol $2.5 \mathrm{mg} / \mathrm{kg} \mathrm{IV}$; atracurium $0.5 \mathrm{mg} / \mathrm{kg} \mathrm{IV}$; isoflurane $1.0 \mathrm{MAC}$; atracurium $0.1 \mathrm{mg} / \mathrm{kg}$ intraoperatively) and a supine intraoperative position was employed.

Further investigations of perioperative radial nerve injuries revealed that, in all the cases, surgical procedures were performed in the same operating room on a newly purchased operating table; intraoperative padding of arms and shoulders had been well done, arm paddings were the same as the paddings on the operating table, but the height of the padded arm board was about $10 \mathrm{~cm}$ higher than the level of operating table. Abduction degree of arm boards had been within the standard range, which according to American Society of Anesthesiologists (ASA) practice advisory, is less than 90 degrees in supine position. ${ }^{2}$ Improper height of the arm boards, leading to compression of the radial nerve between the humerus bone and the edge of arm board, was considered to be the most probable mechanism of injury based on investigations.

Radial nerve injury neither prolonged the patient's stay, nor caused a severe dysfunction. The patients were referred to a physiotherapist after discharge and nonsteroidal anti-inflammatory drugs (NSAIDS) were prescribed as needed during the treatment course of radial neuropathy. Regular follow-up visits were scheduled and all the patients recovered completely without any residual neurologic deficits within 6 months following the surgery.

\section{Discussion}

Peripheral neuropathies are rare, yet potential, complications of surgical procedures and often lead to malpractice claims due to the pain, suffering, and financial issues prompted. ${ }^{3}$ There is plenty of literature regarding various aspects of radial neuropathy. Radial neuropathy as a complication of surgical procedures, however, has not been discussed thoroughly, which can be, in part, due to its low incidence.

Facing neuropathies postoperatively is distinct from similar cases encountered in clinics in several ways: first, the mechanism of the injury is often not known at presentation, primarily since the patient, being 
Table 3: Details of patients who presented with postoperative radial neuropathy

\begin{tabular}{|c|c|c|c|c|c|c|c|c|c|c|}
\hline Patient & Gender & $\begin{array}{l}\text { Age } \\
\text { (years) }\end{array}$ & $\begin{array}{l}\mathrm{BMI} \\
\left(\mathrm{kg} / \mathrm{m}^{2}\right)\end{array}$ & Comorbidity & $\begin{array}{l}\text { Perioperative } \\
\text { MAP (mmHg) }\end{array}$ & $\begin{array}{l}\text { Perioperative } \\
\text { body } \\
\text { temperature } \\
\left({ }^{\circ} \mathrm{C}\right)\end{array}$ & $\begin{array}{l}\text { Nutrition } \\
\text { Status }\end{array}$ & Manifestation & Onset & Outcome \\
\hline 1 & Female & 54 & 29.6 & None & 65-95 & $36.5-37.5$ & Optimal & $\begin{array}{l}\text { Wrist drop, spared } \\
\text { triceps function }\end{array}$ & $\begin{array}{l}\text { Immediately after gaining } \\
\text { consciousness }\end{array}$ & Complete recovery \\
\hline 2 & Male & 61 & 27.3 & None & 65-95 & $36.5-37.5$ & Optimal & $\begin{array}{l}\text { Wrist drop, spared } \\
\text { triceps function }\end{array}$ & $\begin{array}{l}\text { Immediately after gaining } \\
\text { consciousness }\end{array}$ & Complete recovery \\
\hline 4 & Male & 59 & 19.2 & None & 65-95 & $36.5-37.5$ & Optimal & $\begin{array}{l}\text { Wrist drop, spared } \\
\text { triceps function }\end{array}$ & $\begin{array}{l}\text { Immediately after gaining } \\
\text { consciousness }\end{array}$ & Complete recovery \\
\hline 5 & Male & 72 & 21.3 & None & $65-95$ & $36.5-37.5$ & Optimal & $\begin{array}{l}\text { Wrist drop, spared } \\
\text { triceps function }\end{array}$ & $\begin{array}{l}\text { Immediately after gaining } \\
\text { consciousness }\end{array}$ & Complete recovery \\
\hline
\end{tabular}

$B M I=$ body mass index $;$ MAP $=$ mean arterial pressure

Table 4: Details of surgical procedures in the case group

\begin{tabular}{|l|l|l|l|}
\hline Patient & Surgical procedure & $\begin{array}{l}\text { Duration } \\
\text { (decimal hours) }\end{array}$ & $\begin{array}{l}\text { Perioperative } \\
\text { position }\end{array}$ \\
\hline 1 & Laparoscopic cholecystectomy & 3.5 & Supine \\
\hline 2 & Laparoscopic exploration & 5.0 & Supine \\
\hline 3 & Whipple & 7.0 & Supine \\
\hline 4 & Partial colectomy & 6.0 & Supine \\
\hline 5 & Total colectomy & 5.5 & Supine \\
\hline
\end{tabular}

unconscious throughout the procedure, cannot provide additional information. Elucidating the mechanism of injury not only helps the surgeon or anesthesiologist narrow the differential diagnoses, but also is of prime significance to address the causative agent; a process which should be accomplished in a timely manner so that similar scenarios could be prevented. The other difference is that commonly used neurological tests, such as needle electromyography (EMG), are often only useful approximately 4 weeks after the injury; ${ }_{i}^{4}$ hence, the only well-established aid in the early postoperative course to characterize and localize the nerve injury would be physical examinations.

If a patient cannot actively extend their hand and there is also loss of extension of the fingers and thumb, making the patient unable to open the hand before initiating grasp, wrist drop would be among first differential diagnoses considered. Other diagnoses include any insult to the radial nerve along its way, resulting in malfunction of the extensor compartments of the forearm. These consist of damage to the posterior cord, brachial plexus, cervical roots, and the cerebral cortex. ${ }^{4}$ As mentioned above, in the early postoperative course, physical examination plays the key role in ruling out other diagnoses. The cardinal finding to distinguish radial neuropathy from posterior cord lesions via physical examination is the presence of deltoid weakness, in addition to sensory deficit in the shoulder region, which are seen in the latter. One may argue that proximal radial injuries may have a similar presentation to a C7 radiculopathy, and the patient may complain of mild sensory symptoms and signs in the sensory distribution of the radial nerve in dorsal hand. The key to distinguish these two disorders is that radial neuropathy does not cause sensory loss of the palmar aspect of the third finger. In addition, C7 nerve root insults, which are severe enough to prompt muscle weakness, may also affect median-innervated muscles, such as the flexor carpi radialis and pronator teres supplied by the C7 nerve root. Infarcts occurring in the precentral "hand knob" area of the cerebral cortex can also present with an isolated wrist drop, but such cases are also accompanied by signs of upper motor neuron dysfunction such as hyperreflexia. ${ }^{4}$

Medical history of the patient can be of further help in narrowing the differential diagnoses. For instance, rupture of the extensors of thumb and fingers can mimic a partial posterior interosseous nerve lesion, but this disorder is often seen in patients with rheumatoid arthritis or cases of focal myopathies of the extensors of the finger. ${ }^{4}$ Hereditary neuropathy with liability to pressure palsy can also be considered in the differential diagnosis list based on the patient's history. In this disorder, nerves are highly sensitive to pressure and patients present with recurrent limb muscle weakness, tingling and numbness. Taking our patients' characteristics into consideration, none of these differential diagnoses can be determined in this study. One should also bear in mind that it is crucial to exclude other possibilities such as other musculoskeletal injuries, cervical spinal injuries, autoimmune neurologic disorders, ${ }^{5}$ and acute brachial plexitis, ${ }^{6}$ in compatible clinical settings.

After excluding other differential diagnoses for radial nerve palsies, the surgeon or anesthesiologist should look for possible contributors. Perioperative neuropathy can be multifactorial and may occur due to: anesthetic techniques and agents; deep hypothermia as a result of direct skin cooling:7 hypotension:8 under-nutrition or malnutrition;9 or a combination of stretch, compression, and ischemia from a variety of causes such as table edges, table surfaces, restraining straps, retractor systems, ${ }^{10}$ or prolonged inflation of an automatic blood pressure cuff around the arm, particularly in a lean patient. ${ }^{11}$ They may also be idiopathic. ${ }^{3}$ In all patients in the present study who presented with radial neuropathies, general anesthesia had been achieved by routine agents with normal dosages. Furthermore, no hypothermia (core temperature $<36^{\circ} \mathrm{C}$ ) or hypotension (mean arterial pressure $<65 \mathrm{mmHg}$ ) had been detected intraoperatively. The nutrition status of the patients was optimal and there were no comorbidities. 
After ruling out the aforementioned factors, we were left with the possibility of an intraoperative malposition bringing about traction or compression of the radial nerve. Rechecking the arm boards, the abduction degree was within the standard range (less than 90 degrees according to ASA advisory practice), ${ }^{2}$ and thus, traction of the radial nerve was less likely. That left a presumption of a compressive injury of the radial nerve. To continue the discussion, it is noteworthy to remember that the radial nerve is most susceptible to a compressive insult in two areas of the arm: the distal third of the humerus, where this nerve continues its way directly laterally to the bone (where an automatic blood pressure cuff could potentially disturb the nerve); and about $6 \mathrm{~cm}$ centered around the midshaft of the humerus bone (where the arm is usually fixed to the arm board during the surgery). ${ }^{4}$ No prolonged inflation of the blood pressure cuff had been noted during the procedures, so we re-checked the arm board and its fixator to identify the potential cause. We found that during all the operations complicated by a wrist drop, the arm boards were approximately $10 \mathrm{~cm}$ higher than the level of operating table, and hence the most likely mechanism of injury could be compression of the radial nerve between the humerus bone and the edge of the arm board (which was mismatched to the mattress level), since the arm was pulled anteriorly (upwards as the patients were in a supine position). An EMG performed 4 weeks after the surgical procedure revealed a reduction in recruitment pattern and confirmed our presumptive diagnosis in all the patients.

This raises another question: why did this extra force affect only some patients and not all of them? Despite several studies evaluating patient-related factors such as age, ${ }^{12-17}$ gender, ${ }^{3,13-15,17,18}$ weight, ${ }^{19}$ comorbidities (such as diabetes mellitus), ${ }^{20,21}$ tobacco use, and vascular disease, ${ }^{13-15}$ there still seems to be controversy regarding the factors making some individuals vulnerable to perioperative neuropathies. Some authors hold the opinion that the special intraoperative positioning of the patient in addition to a longer duration of operation in major laparoscopic surgeries can increase the risk of development of perioperative nerve injuries, ${ }^{22}$ but in our experience, postoperative wrist drops occurred following laparoscopic surgeries in $40 \%$ (two) of the patients. There was a male predominance (80\% of the patients) in our case group, and our study also showed that less than half of the perioperative radial neuropathies (40\%) occurred in overweight patients.

In cases of compression neuropathies, depending on the force and duration of compression, the nerve may undergo neuropraxia, axonotmesis, and neurotmesis; with neuropraxia being a transient insult to the nerve, and neurotmesis being a complete destruction of axons and Schwann cells. ${ }^{23-25}$ The leading mechanism of injury in our cases, however, was a prolonged conduction block; a concept introduced by Ochoa et al. in the early 1970s. ${ }^{26}$ This pathology occurs as a result of a moderate-intensity compression, during which the node of Ranvier is displaced from its normal location beneath the Schwann cell junction. This causes the paranodal myelin on the side of the node to be stretched on one side of the node, invaginating on the other, which in some cases may lead to a partial or complete rupture of the myelin. Short intercalated segments form with time and remyelination occurs.

The cornerstone of management of intraoperative positioning injuries, is prevention. ${ }^{10}$ However, when encountered, depending upon the extent of the neural damage, treatment of perioperative radial neuropathy may differ from NSAIDS, corticosteroids, and rest with maintaining a passive range of motion to surgical intervention. ${ }^{27}$ It typically takes 5-30 weeks for radial neuropathy to resolve properly. ${ }^{28}$

This study has potential limitations: the first is that we investigated perioperative neuropathies retrospectively, as did Welch et al. in 2009, who retrospectively evaluated perioperative peripheral nerve injuries. ${ }^{29}$ Thus, we cannot come to definitive conclusions regarding the causation of radial nerve injuries that occurred in this study. We have attempted to minimize this limitation by choosing a relatively shorter period of investigation to be able to effectively review all medical records and operation reports. This shorter period also reduced the possibility of surgeons and anesthesiologists forgetting remarkable intraoperative events. The other limitation could be that this study was conducted at a single center and thus multicenter studies carried out on a larger population of patients may yield different incidence of perioperative radial neuropathy. Multicenter prospective studies can be considered in future to further investigate perioperative neuropathies.

\section{Conclusion}

The incidence of perioperative radial neuropathy in this retrospective database review was found to be $0.2 \%(n=5 / 2,400)$, and all the cases manifested as wrist drop. The low incidence of nerve injuries following surgical procedures, particularly those affecting the radial nerve, may cause physicians to overpass this potential complication of surgery. A horizontal division of work between surgeon and anesthesiologist, as well as paying attention to the small details intraoperatively, can reduce the possibility of encountering neuropathies following a surgical procedure. Perioperative neuropathies, especially those with a relatively lower incidence such as radial neuropathies, are among topics in medicine requiring more attention. Surgeons and anesthesiologists can provide a premium source of information regarding these less considered complications notably by sharing their experience in similar cases. $]$
1. Sawyer RJ, Richmond MN, Hickey JD, Jarratt JA. Periphera nerve injuries associated with anaesthesia. Anaesthesia. 2000:55:980-91.

2. Practice advisory for the prevention of perioperative peripheral neuropathies 2018: an updated report by the American Society of Anesthesiologists task force on prevention of perioperative peripheral neuropathies. Anesthesiology. 2018;128:11-26.

3. Kroll DA, Caplan RA, Posner K, et al. Nerve injury associated with anesthesia. Anesthesiology. 1990;73:202-7.

4. Wang LH, Weiss MD. Anatomical, clinical, and electrodiagnostic features of radial neuropathies. Phys Med Rehabil Clin N Am. 2013;24:33-47.

5. Arnason BG, Asbury AK. Idiopathic polyneuritis after surgery. Arch Neurol. 1968;18:500-7.

6. Malamut RI, Marques W, England JD, Sumner AJ. Postsurgical idiopathic brachial neuritis. Muscle Nerve. 1994;17:320-4.

. Stephens J, Appleby S. Polyneuropathy following induced hypothermia. Trans Am Neurol Ass. 1955;80:102-4.

8. Garland H, Moorhouse D. Compressive lesions of the external popliteal (common peroneal) nerve. Br Med J. 1952;2:1373-8.

. Nicholson MJ, Eversole UH. Nerve injuries incident to anaesthesia and operations. Anesth Analg. 1957;36:19-32.

10. Winfree $\mathrm{CJ}$, Kline $\mathrm{DG}$. Intraoperative positioning nerve injuries surg Neurol. 2005;63:5-18.

11. Swei SC, Liou CC, Liu HH, Hung PC. Acute radial nerve injury associated with an automatic blood pressure monitor. Acta Anaesthesiol Taiwanica. 2009,47:147-9.

12. Wong CA, Scavone BM, Dugan $S$, et al. Incidence of postpartum lumbosacral spine and lower extremity nerve injuries. Obstet Gynecol. 2003:101:279-88.

13. Warner MA, Martin JT, Schroeder DR, et al. Lower-extremity moto neuropathy associated with surgery performed on patients in a lithotomy position. Anesthesiology. 1994;81:6-12.

14. Warner MA, Warner DO, Harper CM, et al. Lower extremity neuropathies associated with lithotomy positions. Anesthesiology. 2000; 93:938-42.

15. Warner MA, Warner ME, Martin JT. Ulnar neuropathy. Incidence, outcome, and risk factors in sedated or anesthetized patients.
Anesthesiology. 1994;81:1332-40.

16. Horlocker T, Hebl JR, Gali B, et al. Anesthetic, patient, and surgica risk factors for neurologic complications after prolonged total tourniquet time during total knee arthroplasty. Anesth Analg. 2006;102:950-5

17. Weber ER, Daube JR, Coventry MB. Peripheral neuropathies associated with total hip arthroplasty. J Bone Joint Surg Am. 1976;58:66-9

18. Alvine FG, Schurrer ME. Postoperative ulnar-nerve palsy. Are there predisposing factors? J Bone Joint Surg Am. 1987;69:255-9.

19. Garrigues HJ. Anaesthesia-paralysis. Am J Med SCi. 1897;113:81-9.

20. Jones HD. Ulnar nerve damage following general anaesthetic: a case possible related to diabetes mellitus. Anaesthesia. 1967;22:471-5.

21. Massey EW, Pleet AB. Compression injury of the sciatic nerve during prolonged surgical procedure in a diabetic patient. J Am Geriatr SOC. 1980;28:188-9.

22. Velchuru VR, Domajnko B, de Souza A, et al. Obesity increases the risk of postoperative peripheral neuropathy after 
minimally invasive colon and rectal surgery. Dis Colon Rectum 2014;57:187-93

23. Bumbasirevic M, Palibrk T, Lesic A, Atkinson H. Radial nerve palsy. EFORT Open Rev. 2017:1:286-94.

24. Neal S, Fields KB. Peripheral nerve entrapment and injury in the upper extremity. Am Fam Physician. 2010;81:147-55

25. Floranda $\mathrm{EE}$, Jacobs BC. Evaluation and treatment of upper extremity nerve entrapment syndromes. Prim Care 2013;40:925-43.

26. Ochoa J, Fowler TJ, Gilliatt RW. Anatomical changes in peripheral nerves compressed by a pneumatic tourniquet. J Anat. 1972;113:433-55.

27. Latef $\mathrm{TJ}$, Bilal $\mathrm{M}$, Vetter $\mathrm{M}$, et al. Injury of the radial nerve in the arm: a review. Cureus. 2018;10:e2199.
28. Agrawal HK, Khatkar V, Garg M, et al. An unusual cause of radia nerve palsy. Chin I Traumatol. 2014:17:175-7.

29. Welch MB, Brummett CM, welch TD, et al. Perioperative peripheral nerve injuries: a retrospective study of 380,680 cases during a 10 -year period at a single institution. Anesthesiology. 2009;111:490-7. 